\title{
EXPOSIÇÃO ORAL NO ENSINO SUPERIOR DE QUÍMICA
}

\author{
Patrícia Fernanda de Oliveira Cabrala, Keila Angélica Peron ${ }^{\mathrm{b}, \#}$ e Salete Linhares Queiroz ${ }^{\mathrm{b}, *}$ \\ Instituto de Física, Universidade de São Paulo, 05508-090 São Paulo - SP, Brasil \\ 'Departamento de Físico-Química, Instituto de Química de São Carlos, Universidade de São Paulo, 13566-590 São Carlos - SP, Brasil
}

Recebido em 31/07/2018; aceito em 06/12/2018; publicado na web em 23/01/2019

\begin{abstract}
ORAL PRESENTATION IN UNDERGRADUATE CHEMISTRY TEACHING. Oral presentation (OP) integrates social practices from the academic community, whereby knowledge about the subjects under study can be disseminated and discussed. On the other hand, systematic work is not verified for learning this genre in undergraduate chemistry teaching. In this perspective, this article aims to report on a classroom activity used in a scientific communication course in order to improve the skills needed for chemistry students to develop OP. The students were asked to prepare an OP by reading original research articles published in the Química Nova journal on the subject of biodiesel. The OPs were analyzed according to the Teachable Dimensions of the Oral Presentation Genre so as to indicate both the actions that make the production of this genre feasible and those that hinder it. The results suggest the relevance of commitment to OP teaching and learning in chemistry courses, which is a complex activity, but fundamental for undergraduate education.
\end{abstract}

Keywords: oral presentation; scientific communication; chemistry.

\section{INTRODUÇÃO}

A relevância da comunicação científica para a formação do químico é evidenciada nas Diretrizes Curriculares Nacionais para os Cursos de Química. ${ }^{1}$ Estas apontam para a necessidade de o estudante aprender a "ler, compreender e interpretar os textos científico-tecnológicos", "escrever, apresentar e defender seus achados", "saber comunicar corretamente os projetos e resultados de pesquisa na linguagem científica", dentre outros. Apesar da sua importância, a comunicação científica se constitui em um dos aspectos menos abordados no ensino dessa disciplina. Inclusive em carreiras universitárias, pouca atenção é dada às questões a ela relacionadas, conforme apontam artigos publicados nesta Revista. ${ }^{2-4}$

Desse modo, é possível estabelecer relações entre a situação em pauta e o fato de os professores de química não possuírem à sua disposição volume considerável de estudos que ofereçam fundamentos teórico-metodológicos, capazes de orientá-los nas práticas de ensino realizadas, visando o aperfeiçoamento da comunicação científica dos alunos. Usualmente, os professores adotam livros-texto que enfatizam somente os aspectos estruturais e as características dos textos científicos mais aceitos e difundidos pela comunidade científica, o que não é surpreendente, haja vista que, na área de química, estudos que levam em conta aspectos cognitivos e retóricos envolvidos na produção de gêneros do domínio acadêmico, embora existentes, ${ }^{2-4,5}$ encontram-se em fase preambular. ${ }^{6}$

Uma vez que os gêneros textuais circulantes na esfera acadêmica (resumo, exposição oral, artigo original de pesquisa, relatório de laboratório etc.) são utilizados com frequência para a divulgação dos resultados de trabalhos científicos e ao final de um curso para a obtenção de um título, os estudantes precisam dominar tanto os gêneros orais quanto os escritos, pois em sua trajetória profissional iminente também será necessário que se expressem, a fim de explicitar os conhecimentos adquiridos no ensino superior e ao longo de sua experiência. ${ }^{7}$ Assim sendo, dentre os gêneros citados anteriormente,

*e-mail: salete@iqsc.usp.br

\#Docente do Instituto Federal de Educação, Ciência e Tecnologia de São Paulo, campus de Sertãozinho consideramos a exposição oral (doravante EO), elaborada a partir de artigos originais de pesquisa (doravante AOP), como objeto de estudo.

A EO integra as práticas sociais da comunidade científica, pois a partir dela é possível aprender novos conteúdos, apresentar os resultados encontrados em pesquisas, convencer e defender hipóteses etc. Por outro lado, não são verificados trabalhos sistemáticos para o aprendizado desse gênero em sala de aula, de modo que o mesmo seja utilizado como meio para a obtenção de outros conhecimentos ou para a avaliação dos estudantes. ${ }^{8}$ Assim, a pertinência do trabalho com a EO se dá por meio do desenvolvimento de habilidades como a exploração de diversas fontes de informação, a seleção do texto que será exposto em vista do tema e da intenção do apresentador, a elaboração do material de apoio, o planejamento, a antecipação e a atenção com o auditório. ${ }^{9}$

Partindo desse pressuposto, neste trabalho temos como objetivo principal relatar uma experiência didática aplicada tendo em vista o aprimoramento das habilidades necessárias para a elaboração de EO, por parte de graduandos em química. Estes foram solicitados a elaborar EO a partir da leitura de AOP publicados nesta Revista (textos base), sobre o tema biodiesel. Investigamos a efetividade das EO produzidas pelos referidos alunos a partir da análise das Dimensões Ensináveis do Gênero Exposição Oral, propostas por Dolz et al., ${ }^{9}$ e descritas de forma sucinta a seguir. Dessa forma, pretendemos contribuir para a ampliação de estudos que fornecem subsídios teórico-metodológicos que possam redimensionar as atividades de ensino-aprendizagem desenvolvidas em cursos de química, com o objetivo de desenvolver habilidades exigidas na produção de gêneros.

\section{DIMENSÕES ENSINÁVEIS DO GÊNERO EXPOSIÇÃO ORAL}

Para Bakhtin ${ }^{10}$ os gêneros são compreendidos por nós enquanto membros de uma comunidade. Nesse caso, a EO está inserida dentre as convenções da comunidade acadêmica, que determinam a situação de comunicação na qual o gênero será produzido. Por sua vez, Silva ${ }^{7}$ salienta que os gêneros orais devem ser conhecidos dos graduandos tanto quanto os escritos, já que em um futuro próximo, no âmbito profissional, estes deverão expressar na forma oral os conhecimentos 
adquiridos ao longo do curso. Enquanto, Almeida, Mesquita e Alves ${ }^{11}$ acrescentam que as atividades didáticas pautadas em gêneros orais não descartam as atividades de leitura e escrita, visto que as duas últimas fazem parte do processo de planejamento, direcionamento e organização da temática que será apresentada.

Do ponto de vista didático, Dolz et al. ${ }^{9}$ enfatizam a construção de uma sequência de atividades para ensinar EO aos estudantes. Para tanto, devem ser consideradas três dimensões: a situação de comunicação, as características linguísticas e a organização interna da exposição. Estas estão brevemente descritas a seguir:

Situação de comunicação: dá-se por meio da exposição realizada em sala de aula. Assim, o expositor, responsável pela elaboração de uma apresentação sobre determinada temática, assume o papel de professor temporariamente (fazendo-se valer da ideia de que "é ensinando que se aprende"), enquanto os colegas assumem o papel de ouvintes, com o intuito de aprender sobre o tema, aperfeiçoar ou adquirir conhecimento. Os elementos envolvidos nessa situação são identificados a partir das convenções atribuídas a esse tipo de exposição. Nesse contexto, o papel de especialista deve ficar explícito para o aluno expositor, de forma que ele tome consciência acerca deste e possa guiar o seu próprio comportamento, por meio de perguntas a si mesmo sobre a organização e a capacidade de transmitir as informações do tópico em questão.

Características linguísticas: estas são apresentadas por meio do sistema textual da EO: coesão temática (articulação entre as partes temáticas); sinalização do texto (distinção entre as partes primárias e secundárias; entre as explicações e descrições; entre os desenvolvimentos de conclusões em forma de resumo e as sínteses); introdução de exemplos e reformulações.

A esse respeito, Dolz et al. ${ }^{9}$ citam o trabalho de Goffman, ${ }^{12}$ que destaca que os expositores utilizam recursos como a memorização, a leitura em voz alta e a fala espontânea. Tendo em vista que a última delas seja a desejável, é necessário que se ensine aos alunos como preparar uma EO sem utilizar o recurso da leitura e sim apoios diversos. Tais apoios podem ser gráficos, anotações, citações, dentre outros, integrantes do texto base ou não. É desejável também que o modelo didático preze por aspectos como a compreensão do texto base, a entonação e dicção das palavras, a capacidade de prender a atenção dos espectadores, a marcação de voz que auxilia a estruturação da apresentação, a gestualidade etc.

Organização interna da exposição: Dolz et al. ${ }^{9}$ destacam que embora a EO seja pautada nas interações entre expositor e ouvintes, seu planejamento é realizado apenas pelo primeiro, de modo que há uma boa oportunidade para analisar a sua capacidade de planejar um texto. Além disso, é importante observar a organização interna inerente a $\mathrm{EO}$, conforme as partes a seguir:

1) Abertura: momento de apresentação do expositor aos espectadores. Pode ser realizada pela introdução por parte de uma terceira pessoa e nem sempre recebe a devida atenção em situações de ensino;

2) Introdução ao tema: tem por objetivo despertar o interesse/ atenção/curiosidade dos ouvintes;

3) Apresentação do plano: demonstra as etapas de planejamento realizadas pelo expositor, para além da enumeração de ideias ou tópicos, de modo que é possível verificar se a sequência proposta por ele é adequada;

4) Desenvolvimento e encadeamento dos diferentes temas: corresponde aos tópicos enumerados previamente na apresentação do plano;

5) Recapitulação e síntese: possibilita retomar os pontos impor- tantes da EO e representa a transição entre o desenvolvimento e as fases de finalização;

6) Conclusão: conduz à "mensagem final", que pode conter uma introdução a novos problemas gerados a partir da EO ou iniciar um debate;

7) Encerramento: assemelha-se à abertura e inclui agradecimentos ao auditório. Pode conter situações de interação distintas das ocorridas na etapa de desenvolvimento, por meio de intervenções do mediador ou dos espectadores.

Neste trabalho as referidas dimensões foram empregadas para subsidiar a identificação de como os estudantes modificaram o texto dos AOP para as EO e quais recursos foram utilizados para tal. A situação de comunicação investigada foi caracterizada como EO ocorridas em disciplina de comunicação científica. Nesse contexto, analisamos a organização interna de EO elaboradas pelos alunos e comentamos sobre as características linguísticas evidenciadas. Salientamos que tal análise não abrange as especificidades das imagens utilizadas nos slides, mas sim a disposição dos mesmos na apresentação e sua utilização por parte dos alunos. Essa análise pode fornecer subsídios aos professores no planejamento de atividades desse tipo, bem como na avaliação de EO produzidas pelos alunos a partir da literatura primária em química.

\section{PERCURSO METODOLÓGICO}

As atividades didáticas foram aplicadas a alunos matriculados na disciplina de Comunicação e Expressão em Linguagem Científica II (dois créditos teóricos, um crédito trabalho), na ocasião oferecida no segundo semestre do curso de Bacharelado em Química do Instituto de Química de São Carlos (IQSC) da Universidade de São Paulo. A conveniência da aplicação da proposta na referida disciplina se deve ao fato do seu principal objetivo consistir no aprimoramento das capacidades de escrita, leitura e comunicação oral dos estudantes, e não o ensino de conteúdos específicos de química. Essa busca ainda promover o aperfeiçoamento de assuntos correlatos estudados na disciplina de Comunicação e Expressão em Linguagem Científica I e fornecer aos alunos subsídios que lhes permitam a realização de uma leitura crítica da literatura primária em química. Essa se caracteriza pela leitura das entrelinhas do texto, que ultrapassa a leitura das informações dispostas e permite ao leitor interpretar e refletir sobre o seu conteúdo, produzindo inferências por meio da produção de sentidos pautada na reunião de informações disponibilizadas e/ou da inserção de novos conhecimentos. ${ }^{13}$ Tal peculiaridade favorece o emprego de práticas envolvendo a elaboração de EO.

As atividades de produção de EO estiveram vinculadas à aplicação de um processo de peer review (doravante PPR), assim como utilizado pela comunidade científica para a avaliação dos trabalhos redigidos por pesquisadores engajados na mesma área de conhecimento. O PPR, quando empregado como uma estratégia didática, tem finalidades distintas, como a promoção do entendimento sobre a importância da produção escrita na comunidade científica e o desenvolvimento da habilidade de leitura crítica, além do aprofundamento no entendimento de conceitos. ${ }^{14} \mathrm{O}$ propósito principal da aplicação do PPR na disciplina foi o de entendimento dos conteúdos expressos nos AOP por parte dos estudantes, o que seria agente causador de impacto nas EO.

No semestre de aplicação da proposta, os sujeitos foram os estudantes que participaram de todas as etapas que serão descritas a seguir e autorizaram a utilização das informações coletadas por meio da assinatura de um Termo de Consentimento Livre e Esclarecido, onde constam as normas éticas da pesquisa e seus objetivos. Assim, analisamos os resultados obtidos por 12 alunos, que elaboraram $\mathrm{EO}$ a partir de $\mathrm{AOP}$ sobre técnicas relacionadas à purificação no 
processo de produção de biodiesel. Para a realização das atividades, os alunos efetuaram leitura crítica orientada pelo professor dos artigos apresentados na Tabela 1, extraídos desta Revista e selecionados por ele previamente. Cada grupo de alunos fez a leitura de um AOP.

Tabela 1. Artigos originais de pesquisa provenientes da Revista Química Nova, utilizados durante o semestre de aplicação da proposta e códigos correspondentes

\begin{tabular}{ll}
\hline Artigo & Título e local de publicação do artigo original de pesquisa \\
\hline AOP1 & $\begin{array}{l}\text { Tratamento de efluente do biodiesel utilizando a eletrocoagulação/ } \\
\text { flotação: investigação dos parâmetros operacionais (v.35, n.2, } \\
\text { p.235-240, 2012). }\end{array}$ \\
\hline AOP2 & $\begin{array}{l}\text { Tratamento da água de purificação do biodiesel utilizando eletro- } \\
\text { floculação (v.35, n.4, p.728-732, 2012). }\end{array}$ \\
\hline AOP3 & $\begin{array}{l}\text { Utilização de argilas para purificação de biodiesel (v.34, n.1, } \\
\text { p.91-95, 2011). }\end{array}$ \\
\hline
\end{tabular}

Todos os artigos tratam da temática biodiesel e foram escolhidos por abordarem apenas técnicas analíticas de fácil compreensão. A delimitação da escolha dos artigos com base neste último critério foi devido ao fato dos alunos, ainda no segundo semestre do curso, não possuírem conhecimentos acerca de determinados princípios de química, imprescindíveis para o entendimento de técnicas analíticas mais sofisticadas. Cabe destacar ainda que mais dois critérios foram levados em conta na escolha dos artigos, com base nas considerações de Santos e Queiroz. ${ }^{15}$ Os autores sugerem que existe a preferência dos alunos pela leitura de artigos originais de pesquisa que "não são demasiadamente extensos e que privilegiam a reflexão e a discussão sobre aspectos não apenas científicos, mas também tecnológicos e sociais" (p. 193).

As atividades na disciplina foram realizadas individualmente e em grupo. Foram formados três grupos (doravante G1, G2 e G3), compostos por quatro alunos cada, cujas EO foram selecionadas para análise neste trabalho. No primeiro dia de aula, o professor informou sobre o conteúdo a ser ministrado na disciplina, seus principais objetivos e procedimentos. Nas semanas seguintes, individualmente, cada aluno concluiu três atividades que consistiam na resolução de questões concernentes ao artigo estudado. Nesse ínterim, foi também ministrada aula expositiva na qual o professor fez considerações sobre a preparação e apresentação de trabalhos orais e de painéis. Essas considerações foram tecidas no sentido de apresentar aos alunos a organização interna inerente às EO, na perspectiva descrita no tópico anterior: Dimensões Ensináveis do Gênero Exposição Oral.

$\mathrm{Na}$ semana seguinte à aula expositiva foi iniciado o PPR, que ocorreu parcialmente em horário extraclasse e concomitantemente à realização das seguintes atividades relacionadas ao AOP: EO das seções "Introdução" e "Parte Experimental" (com ênfase nas técnicas empregadas), EO do artigo completo, apresentação oral de painel sobre o artigo e reapresentação oral do artigo. Em cada uma das quatro ocasiões, o grupo foi representado por um integrante. As apresentações foram feitas em PowerPoint e tiveram a duração de dez ou vinte minutos, dependendo da sua natureza. Após as apresentações orais do artigo completo, os alunos tiveram dez minutos para formular perguntas aos alunos expositores, representantes de cada um dos grupos, e estes tiveram, aproximadamente, o mesmo período de tempo para respondê-las, contando com o auxílio dos demais membros do seu grupo.

Cabe destacar que neste trabalho são analisadas as EO sobre o artigo completo. É ainda muito importante reforçar o papel fundamental que o PPR desempenhou na elaboração das EO, uma vez que o seu desencadeamento forneceu elementos para que a leitura dos AOP fosse realizada de forma crítica e criteriosa. Por essa razão, o PPR encontra-se detalhadamente descrito a seguir.

\section{Preparação, aplicação e avaliação do PPR}

Antes do desencadeamento do PPR na disciplina de comunicação científica, os alunos participaram de uma aula que foi idealizada com o intuito de prepará-los para a produção de um texto argumentativo, que seria o produto a ser avaliado no processo. Esse deveria ser redigido com base em informações contidas no artigo estudado pelo grupo. Nessa perspectiva, o professor fez uma breve exposição sobre as características inerentes a um texto argumentativo e, em seguida, propôs aos alunos que participassem de um jogo argumentativo. ${ }^{16}$ Para tanto, cada um dos seis grupos elaborou, em um intervalo de vinte minutos, um bom argumento sobre o porquê do seu merecimento a uma caixa de chocolates.

Os alunos foram informados que as razões para o merecimento do prêmio poderiam ser reais ou imaginárias, formais ou informais, direcionadas para um membro da equipe ou à equipe inteira. $\mathrm{O}$ professor até então não exerceu nenhuma influência sobre os argumentos dos alunos. Concluída a elaboração do argumento, este foi apresentado oralmente por um integrante de cada grupo. Após as apresentações dos grupos, um material com definições e exemplos de componentes do argumento, segundo Toulmin, ${ }^{17}$ foi entregue a cada um deles. Com o apoio desse material, os alunos tentaram identificar a existência dos componentes nos argumentos por eles elaborados para justificar o merecimento do grupo ao prêmio. Ou seja, os alunos tentaram identificar tais componentes em seus próprios argumentos, que foram também analisados pelo professor, o que permitiu o alcance de um consenso sobre o grupo vencedor.

Concluído o jogo, o professor esclareceu aos alunos que os conhecimentos adquiridos na aula sobre a estrutura de um "bom argumento" deveriam ser usados na produção de um texto argumentativo individual sobre a temática em foco no artigo em estudo. Dessa forma, solicitou que cada grupo escrevesse no quadro negro, no formato de questionamento, o problema principal tratado no artigo, assim como a quantidade de soluções indicadas pelos autores. A Tabela 2 ilustra o problema principal em estudo em cada um dos artigos e o número de soluções apontadas para cada um deles, segundo o entendimento dos grupos.

Tendo sido discutida a pertinência dos questionamentos apresentados por cada um dos grupos, os alunos foram incumbidos de escrever um texto sobre os problemas elencados e argumentar a favor de uma solução, que poderia ter sido, ou não, mencionada pelos autores do artigo. Com os textos em questão em mãos, o PPR foi então desencadeado pelo professor. O processo ocorreu em quatro

Tabela 2. Problema principal em estudo nos AOP e número de soluções apontadas pelos autores

\begin{tabular}{cccc}
\hline Grupo & Artigo & Problema principal em estudo & $\begin{array}{c}\mathrm{N}^{\circ} \text { de soluções } \\
\text { apontadas }\end{array}$ \\
\hline G1 & AOP1 & Qual o melhor método para tratar o efluente do biodiesel? & 3 \\
G2 & AOP2 & Qual a melhor maneira de purificar a água que resulta do processo de purificação do biodiesel? & 2 \\
G3 & AOP3 & Como fazer a purificação do biodiesel? & 3 \\
\hline
\end{tabular}


ciclos, divididos em dezesseis etapas. A Figura 1 demonstra esquematicamente os ciclos e etapas do PPR, de maneira a sintetizar parte do texto apresentado a seguir.

\section{Primeiro ciclo do PPR}

O primeiro ciclo foi dividido em cinco etapas:

Etapa 1: produção de texto inicial (número de palavras livre), individualmente e em horário extraclasse.

Etapa 2: envio do texto via e-mail pelos alunos ao professor.

Etapa 3: impressão de três cópias do texto enviado por cada um dos autores, sem identificação dos mesmos.

Etapa 4: distribuição, em sala de aula, de questionário de caracterização dos alunos, tendo em vista o conhecimento sobre as suas concepções e experiências prévias referentes ao PPR, e entrega dos textos dos alunos autores aos alunos avaliadores. Os textos distribuídos foram acompanhados de orientações sobre o procedimento de avaliação e solicitação de elaboração de critérios de avaliação. Cada aluno avaliador recebeu três textos.

Etapa 5: redação pelos alunos, em sala de aula, de avaliação dos textos analisados e indicação dos critérios utilizados para tanto. Entrega ao professor dos documentos produzidos nesta aula: critérios de avaliação empregados e avaliações propriamente ditas dos textos.

\section{Segundo ciclo do PPR}

Já o segundo ciclo foi dividido em mais três etapas:

Etapa 6: elaboração de rubrica (Quadro 1S, material suplementar) por parte do professor, com base na leitura de todos os critérios de avaliação sugeridos pelos alunos na etapa 5 e de considerações apresentadas em sala de aula sobre os componentes do argumento. ${ }^{17}$

Etapa 7: apresentação por parte do professor da rubrica e

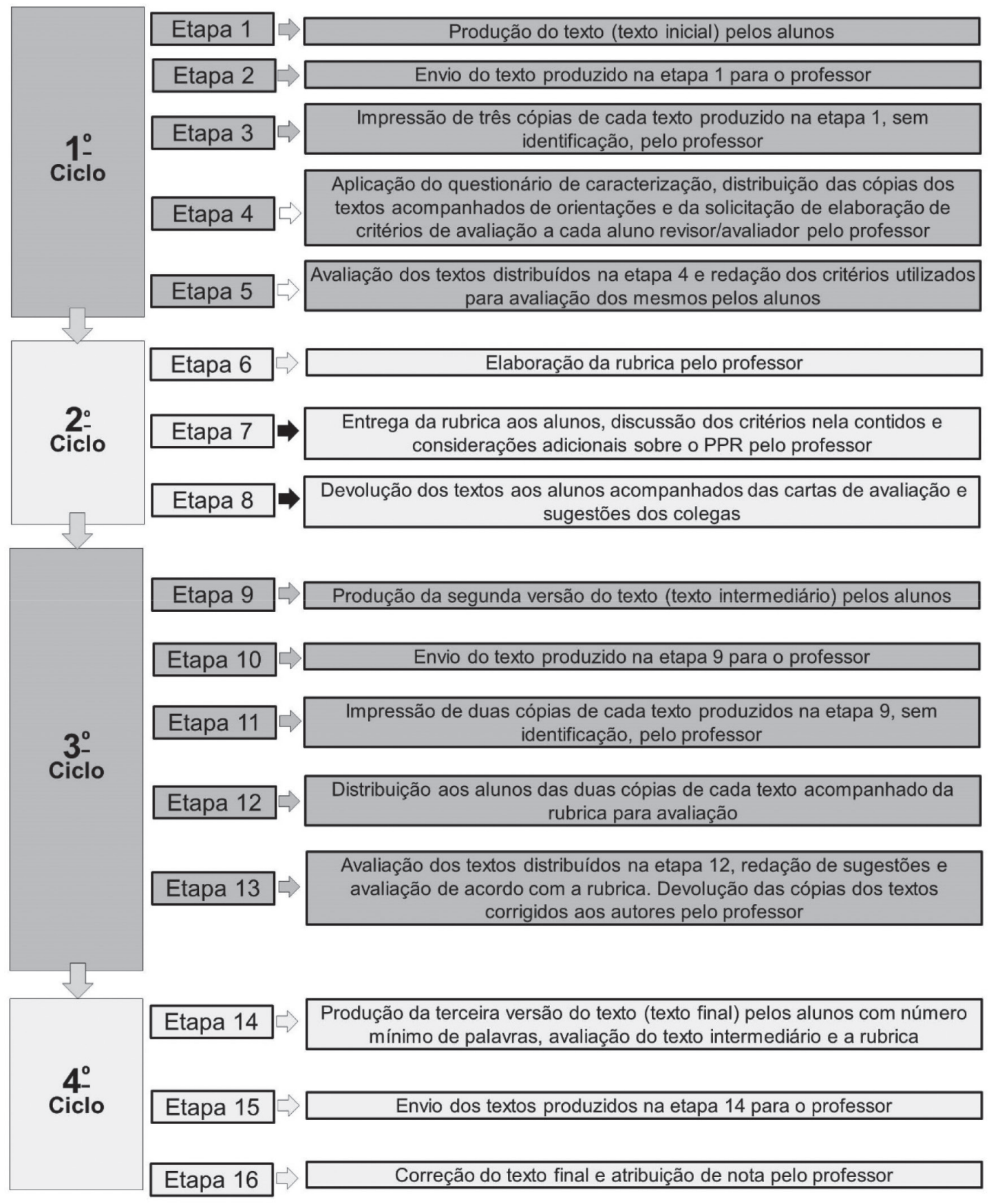

Figura 1. Esquema representativo do PPR 
discussão com os alunos dos critérios nela contidos, além de considerações adicionais sobre o PPR (princípios e procedimentos que tornam o processo mais eficaz, dentre outras). Entrega por parte do professor da rubrica aos alunos, que deveria pautar as próximas avaliações no PPR.

Etapa 8: devolução dos textos aos alunos, acompanhados das cartas de avaliação e sugestões dos colegas.

\section{Terceiro ciclo do PPR}

O terceiro ciclo dividiu-se em mais cinco etapas:

Etapa 9: produção pelos alunos, em horário extraclasse, da segunda versão do texto argumentativo com, no mínimo, oitocentas palavras, tendo por base a avaliação fornecida pelos colegas avaliadores e os critérios ilustrados na rubrica fornecida pelo professor na aula anterior.

Etapa 10: envio da segunda versão do texto (doravante denominado de texto intermediário) via e-mail pelos alunos para o professor.

Etapa 11: impressão de duas cópias do texto de cada um dos autores, sem identificação dos mesmos.

Etapa 12: distribuição dos textos dos alunos autores aos alunos avaliadores. Cada aluno avaliador recebeu dois textos para avaliação em sala de aula. Entrega ao professor das avaliações geradas sobre os textos.

Etapa 13: entrega por parte do professor dos textos intermediários aos alunos autores, acompanhados da avaliação dos colegas.

\section{Quarto ciclo do PPR}

O quarto e último ciclo foi fragmentado em mais três etapas:

Etapa 14: produção pelos alunos, em horário extraclasse, da terceira versão do texto argumentativo com, no mínimo, oitocentas palavras, tendo por base a avaliação fornecida pelos colegas avaliadores e os critérios ilustrados na rubrica fornecida pelo professor.

Etapa 15: envio da terceira versão do texto (doravante denominado de texto final) via e-mail pelos alunos para o professor.

Etapa 16: avaliação e atribuição de nota ao texto final pelo professor.

A partir das etapas descritas anteriormente, analisamos os slides produzidos pelos estudantes para dar suporte às EO sobre o artigo completo. Além disso, transcrições de trechos da fala dos alunos expositores também serão apresentadas na análise.

\section{RESULTADOS E DISCUSSÃO}

Nesta seção, apresentamos a análise do conjunto de slides elaborados pelos integrantes dos grupos. O tempo de apresentação de cada grupo, bem como o número de slides produzidos por cada um deles está apresentado a seguir (Tabela 3):

Verificamos que o grupo G2 produziu maior número de slides e apresentou a EO em maior tempo, seguido por G1 e G3. No que se refere às Dimensões Ensináveis do Gênero Exposição Oral, nos
Tabela 3. Tempo de apresentação e número de slides por grupo

\begin{tabular}{ccc}
\hline Grupo & Tempo de apresentação & Número de slides \\
\hline G1 & 15 minutos & 18 \\
G2 & 18 minutos & 20 \\
G3 & 13 minutos & 14 \\
\hline
\end{tabular}

atentaremos à organização interna de cada EO e, a partir disso, realizamos comentários acerca das características linguísticas, conforme mencionado anteriormente. Em síntese, verificamos que as partes da EO propostas por Dolz et al. ${ }^{9}$ foram evidenciadas em sua maioria. Assim, a Tabela 4 ilustra de forma sintética como se deu a organização interna da EO de cada um dos grupos.

A partir dos dados dispostos na Tabela 4, neste trabalho iremos discutir detalhadamente os dados de G2, que apresentou maior número de slides. Uma vez que as demais EO apresentam algumas particularidades no que se refere à produção do gênero, as características das EO de G1 e G3 serão contrapostas às da EO de G2. Dessa forma, a análise parcial de dois grupos, somada à análise detalhada de um deles tornará possível investigar a efetividade na elaboração da EO por parte dos estudantes, de acordo com as dimensões ensináveis, assim como a tessitura de considerações que podem ser valiosas aos professores no que diz respeito ao domínio e às fragilidades dos alunos em situações de EO.

O grupo G2 foi responsável pela leitura do artigo intitulado "Tratamento da água de purificação do biodiesel utilizando eletrofloculação". ${ }^{18}$ O AOP2 trata da necessidade de otimização do processo de produção de biodiesel, por conta do grande volume de água utilizado em suas etapas, que não pode ser descartado no ambiente sem o procedimento adequado. O referido processo apresenta, além do biodiesel, a glicerina e o sabão como resíduos reaproveitados pela indústria. A partir disso, os autores propõem em seu trabalho a técnica de eletrofloculação como uma forma barata, eficiente e viável de método para a água de purificação do biodiesel, que possibilita a sua reutilização no processo. Alternativas de tratamento são citadas, como a purificação do biodiesel por meio do uso de adsorventes, que não se mostrou uma técnica eficiente para o uso em escala industrial.

O grupo G1 foi responsável pela leitura do artigo intitulado "Tratamento do efluente do biodiesel utilizando a eletrocoagulação/ flotação: investigação dos parâmetros operacionais", ${ }^{19}$ que trata do processo de eletrocoagulação/flotação para o tratamento da água residual do processo de produção do biodiesel utilizando eletrodos de alumínio. A partir de trabalhos reportados na literatura, alguns parâmetros operacionais foram testados pelos autores do AOP1, como um valor de $\mathrm{pH}$ inicial, a distância entre os eletrodos e o tempo de reação. Alternativas foram citadas, como o tratamento biológico, com o uso do ácido sulfúrico para recuperar o biodiesel do efluente.

O grupo G3 foi responsável pela leitura do artigo intitulado "Utilização de argilas para purificação de biodiesel", ${ }^{20}$ que trata da

Tabela 4. Síntese da organização interna da EO dos grupos G1, G2 e G3

\begin{tabular}{|c|c|c|c|}
\hline Organização interna da EO do grupo G2 & G1 & $\mathrm{G} 2$ & G3 \\
\hline 1) Abertura & Slide 1 & Slide 1 & Slide 1 \\
\hline 2) Introdução ao tema & - & - & - \\
\hline 3) Apresentação do plano de exposição & Slide 2 & Slide 2 & Slide 2 \\
\hline 4) Desenvolvimento e encadeamento dos diferentes temas & Slides de 3 a 14 & Slides de 3 a 19 & Slides de 3 a 13 \\
\hline 5) Recapitulação e síntese & - & - & - \\
\hline 6) Conclusão & Slide 15 & Slide 20 & Slide 14 \\
\hline 7) Encerramento & Slide 18 & - & - \\
\hline
\end{tabular}


avaliação da eficácia da purificação de biodiesel metílico de óleo de soja descartado de processos de frituras, por meio das técnicas de lavagem com água destilada, adsorção e destilação em bauxita, bentonita e atapulgita. Além disso, foi apresentada a comparação entre os métodos de purificação e foi verificada a remoção do material insaponificável, contaminação total, glicerina livre e sabão. Os resultados demonstraram que a purificação a seco é uma alternativa possível para o biodiesel do ponto de vista econômico e ambiental, pois as argilas nacionais apresentam baixo custo e podem ser reutilizadas pelo processo de reativação.

\section{Estrutura da EO: suas partes e subpartes}

Segundo Dolz et al., ${ }^{9}$ a exposição oral pode ser dividida em partes e subpartes, que organizam e permitem diferenciar as fases de sua organização. Apresentamos a seguir a classificação e a discussão para os slides produzidos pelos grupos. Cabe destacar que algumas dessas partes não estão necessariamente presentes no conteúdo dos slides, de modo que são passíveis de observação somente a partir da transcrição da fala do aluno expositor. A partir dessa classificação, discutiremos cada uma das partes dispostas na Tabela 4, destacando a produção do $\mathrm{G} 2$, conforme mencionado.

\section{Abertura e introdução ao tema}

Para Dolz et al. ${ }^{9}$ a abertura é caracterizada pelo cumprimento do aluno expositor aos espectadores e pela sua apresentação, que o coloca na posição de especialista em relação à temática que será apresentada. Ainda segundo os autores, esta é uma atividade bastante "ritualizada" e muitas vezes é entreposta por um mediador, em nosso caso, o professor responsável. O aluno expositor de $\mathrm{G} 2$ realizou essas etapas, conforme o slide 1, ilustrado na Figura 2.

\section{Tratamento da Água de Purificação do Biodiesel Utilizando Eletrofloculação}

\begin{abstract}
Juliana Ferreira de Brito, Laís de Oliveira Ferreira, Joaquim Paulo da Silva.(Departamento de ciências exatas, Universidade de Lavras - MG-Brasil)

Teodorico Castro Ramalho.(Departamento de química Universidade de Lavras MG-Brasil)
\end{abstract}

Figura 2. Slide 1 da apresentação do grupo G2

Um trecho da transcrição para o referido slide auxilia na detecção da abertura:

Bom, primeiramente bom dia a todos. Eu gostaria de agradecer a professora doutora pela oportunidade da apresentação e também ao meu grupo (...), por todo o apoio, por toda força e pela ajuda.

Dolz et al. ${ }^{9}$ tecem uma crítica em relação à pouca importância dada a esse momento em situações de sala de aula, visto que, em muitos casos, o professor solicita para que o aluno vá para frente da sala e a EO se inicia, pulando esta etapa. Conforme o trecho da transcrição acima, verificamos que isto não ocorreu, de modo que o aluno expositor cumprimentou a todos, agradeceu ao professor pela oportunidade da apresentação e aos colegas de grupo. Esta atividade é relevante, pois define a situação de comunicação, os papeis e as finalidades da EO que será conduzida.
Ainda que o professor e os demais integrantes do grupo G2 sejam conhecidos de todos os presentes, o fato de citá-los e agradecê-los atinge um dos requisitos da construção do gênero EO. A introdução ao tema é delimitada como o momento de introdução no discurso, no qual há a apresentação e delimitação do tema. Assim, o aluno expositor pode justificar as suas escolhas, a sua motivação e o ponto de vista adotado para a apresentação da EO. ${ }^{9}$ Assim como o G2, os grupos G1 e G3 realizaram esta etapa, de modo que os alunos expositores apresentaram a si mesmos e o restante do grupo, cumprimentaram os colegas e agradeceram o professor, enquanto mediador da EO.

A introdução ao tema é realizada na sequência, conforme o trecho da transcrição do grupo G2 abaixo, também referente ao slide 1:

Hoje eu gostaria de falar um pouquinho mais sobre o tratamento da água de purificação do biodiesel utilizando a eletroflouculação.

Por outro lado, o aluno expositor não referenciou a autoria do AOP2, ainda que esta estivesse disposta no conteúdo do slide, de modo que os nomes dos autores do texto base não fizeram parte da estrutura do gênero produzido. As particularidades da introdução ao tema também não foram evidenciadas em relação ao planejamento da exposição, de modo que as motivações, as razões para as escolhas do autor e a delimitação do tema não foram explicitadas.

Para Dolz et al., ${ }^{9}$ esse é o momento de despertar a atenção e o interesse do público, porém, o aluno expositor não realizou nenhuma explicação capaz de despertar tal interesse na abertura da EO. Nessa ocasião, seria interessante que o aluno expositor compartilhasse alguma informação que julgasse interessante acerca do AOP2, visto que a sua leitura era obrigatória apenas para os integrantes do seu próprio grupo. No que se refere aos grupos G1 e G3, os alunos expositores citaram a temática que seria tratada, por meio do nome do AOP, assim como ocorrido no grupo G2. Além disso, o aluno expositor do grupo G1, de maneira distinta dos demais grupos, indicou os autores do AOP1 nos slides e comentou que os mesmos são pesquisadores de uma universidade localizada no estado da Paraíba.

\section{Apresentação do plano}

Este momento é o de delimitação do assunto que será tratado na EO e se configura como uma etapa na qual se tornam evidentes, para o aluno expositor e para os espectadores, o planejamento, ${ }^{9}$ que inclui os objetivos e ideias que orientam a exposição. ${ }^{21}$ Assim, a etapa se mostra duplamente eficaz, esclarecendo o texto, enquanto produto do planejamento, e o planejamento em si. ${ }^{9}$ Dessa forma, o acompanhamento dos tópicos que foram abordados na EO e que auxiliam no entendimento do planejamento foram introduzidos no slide 2, além de uma imagem (Figura 3). Cabe destacar que as imagens utilizadas pelos estudantes nos slides expostos neste trabalho foram encontradas mediante a ferramenta online Google Imagens ${ }^{\circledR}$ ou pertenciam ao conteúdo do AOP (slides 14 e 16, discutidos posteriormente).

Um trecho da transcrição da EO do grupo G2 demonstra o plano de exposição:

Então, primeiramente eu vou dar uma rápida introdução sobre o biodiesel no atual contexto. É, vou falar as principais, as que mais se destacam, as principais vantagens e desvantagens. Vou apresentar o processo de produção e a questão problema do processo de produção e aí eu vou explanar um pouquinho mais sobre as alternativas de reutilização da lavagem especificamente.

A partir do trecho transcrito, observamos que o aluno expositor enumera os tópicos que serão apresentados por ele durante a EO. Para Silva ${ }^{21}$ os organizadores temporais (primeiro, segundo, depois etc.) possibilitam perceber quais os temas serão tratados e auxiliam 


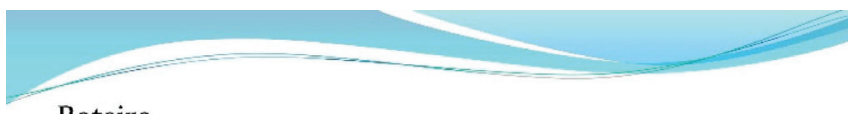

Roteiro

- Introdução: Biodiesel no atual contexto social e econômico;

- Principais vantagens e desvantagens;

- Processo de produção;

- Alternativas de otimização da lavagem no processo de purificação.

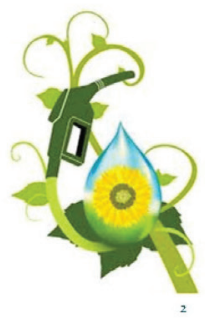

Figura 3. Slide 2 da apresentação do grupo G2

na compreensão do público acerca da sequência textual da EO. Dessa forma, a apresentação do plano da exposição sugere o domínio, ainda que parcial, da estrutura do gênero elaborado. O aluno expositor destacou a inserção de uma breve introdução sobre a temática em questão, depois a apresentação de suas vantagens e desvantagens, seguida da apresentação do processo de obtenção do biodiesel. Tais tópicos foram inseridos por ele, a fim de potencializar o entendimento dos espectadores.

Houve a inserção de informações ao conteúdo do AOP2, mesclando o que seria apresentado aos espectadores, de modo que a contextualização do tema marca o modo de organização da EO, que oferece uma visão amplificada do assunto, para depois entrar no tema específico da purificação da água de lavagem do biodiesel. Tal comportamento demonstra o envolvimento do aluno expositor com o tema. Cabe destacar que a elaboração de um plano de exposição foi recomendada pelo professor na aula de preparação sobre o gênero EO, de acordo com o livro texto adotado na disciplina. ${ }^{22}$ Os autores destacam que "pode ser apresentado um esboço ou resumo do que será exposto, para que as pessoas possam tomar conhecimento do assunto a ser abordado" (p. 41).

Silva ${ }^{21}$ salienta a importância do plano de exposição para os espectadores, de modo que eles possam ter a compreensão das partes que serão abordadas. De fato, em muitas ocasiões esses não têm conhecimento detalhado acerca do tema que será exposto, assim, tal organização pode favorecer o entendimento acerca do desenvolvimento das ideias que serão apresentadas na sequência. Em relação aos demais grupos, ambos cumpriram a etapa de apresentação do plano, porém, de formas distintas. O aluno expositor de G1 realizou a apresentação do plano de acordo com o seu entendimento sobre o AOP. Assim como ocorrido para o grupo G2, não foram utilizadas as mesmas seções contidas no texto base, mas sim títulos elaborados pelo grupo. Por outro lado, o aluno expositor de G3 apresentou o plano seguindo exatamente as mesmas seções do AOP (Introdução, Parte Experimental, Resultados e Discussão e Conclusão).

\section{Desenvolvimento e desencadeamento dos diferentes temas}

Segundo Dolz et al., ${ }^{9}$ o desenvolvimento e o desencadeamento dos diferentes temas devem seguir a numeração disposta no plano de exposição. Destacamos que no slide 2, referente ao plano, não foram utilizados números que indicassem os tópicos a serem expostos. Por outro lado, o aluno expositor organizou suas ideias na mesma ordem de tópicos, conforme os slides 3 (vantagens), 5 (desvantagens), 6 (processo de produção) e 10 (tratamento utilizando eletrofloculação), conforme ilustra a Figura 4.
Destacamos que a introdução, disposta no plano, não foi expressa nos slides, mas sim na fala do aluno expositor, conforme o trecho da transcrição a seguir:

Então, nós sabemos que o crescimento e o desenvolvimento industrial e econômico gerou grandes demandas por fontes de energia. É, questões, problemas econômicos, sociais... E aí surgiram as fontes de energia renováveis como uma alternativa, né? Como uma solução a esses problemas, entre os biocombustíveis, o biodiesel se destaca bastante.

De acordo com a transcrição, o aluno expositor tratou da Introdução conforme o tópico do slide 2 (Figura 3), referente ao plano de exposição ("Introdução: Biodiesel no atual contexto social e econômico"). Notamos que o contexto social, expresso no slide, não foi considerado, de forma a desfalcar o plano, indicando o domínio parcial do gênero produzido. Silva ${ }^{21}$ salienta que essa etapa se caracteriza como central na EO, e sendo assim, é nela que a efetividade na elaboração do gênero EO se dá, essencialmente. Em contraponto, os grupos G1 e G3 seguiram os tópicos elencados em seus respectivos planos de exposição durante a apresentação.

Na EO do grupo G2 observamos que a etapa em questão se constitui dos slides 3 a 19, e, portanto, representa a maior parte da exposição. Nesse sentido, o aluno expositor apresentou pontos de vista construídos a partir das ideias dispostas no AOP2 ou de pesquisas realizadas pelo grupo e também da construção de opiniões pessoais a partir da leitura do texto base. A Figura 5 ilustra exemplos de slides pertencentes a essa etapa, que serão discutidos na sequência.

Assim sendo, identificamos na maior parte dos slides a característica de retomada. Essa se dá pela citação direta ou indireta de trechos do texto base. ${ }^{23}$ As retomadas foram acompanhadas de outras características. No que se refere à retomada acompanhada de eliminação de informações, observamos apenas uma vez a sua ocorrência, no slide 1, na qual os nomes dos autores do AOP2 foram eliminados da fala do aluno expositor:

[RETOMADA] Tratamento da água de purificação do biodiesel utilizando a eletroflouculação... [ELIMINAÇÃO].

Salientamos também, os momentos nos quais a retomada foi precedida e/ou antecedida por acréscimos de informações, como no trecho da transcrição do slide 7:

[RETOMADA] Essa água de lavagem é composta principalmente por sabões de sódio, ácidos graxos, resíduos de glicerina, de $\mathrm{NaOH}$, que é o catalisador que foi utilizado no processo, de etanol. Enfim, de resíduos que foram sendo carregados durante todo seu processo de produção. [ACRÉSCIMO] Aqui nós temos essa imagem que exemplifica a glicerina e o sabão. [RETOMADA] Bom... esse processo de lavagem é extremamente efetivo na remoção de todos esses resíduos, porém ele é muito dispendioso porque ele utiliza um grande volume de água. Para purificação de um litro de biodiesel são necessários três litros de água. Então é um processo extremamente dispendioso que é uma desvantagem... porque. É, pensem vocês...

A partir do trecho transcrito fica evidente a leitura mais ativa por parte do aluno expositor, visto que há a concordância com as ideias dispostas no AOP2. Porém, a partir de seu julgamento, ocorre o acréscimo de novas informações que possam potencializar o entendimento dos espectadores. $\mathrm{O}$ acréscimo pode ter sido realizado a partir de dúvidas do próprio aluno expositor, já que esse se encontra no mesmo nível de instrução dos espectadores: seus colegas de turma. A reformulação de ideias também aponta 


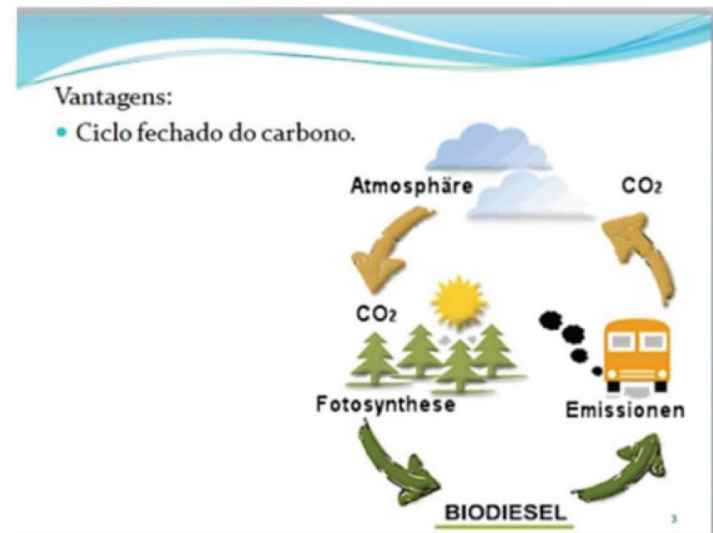

Slide 3

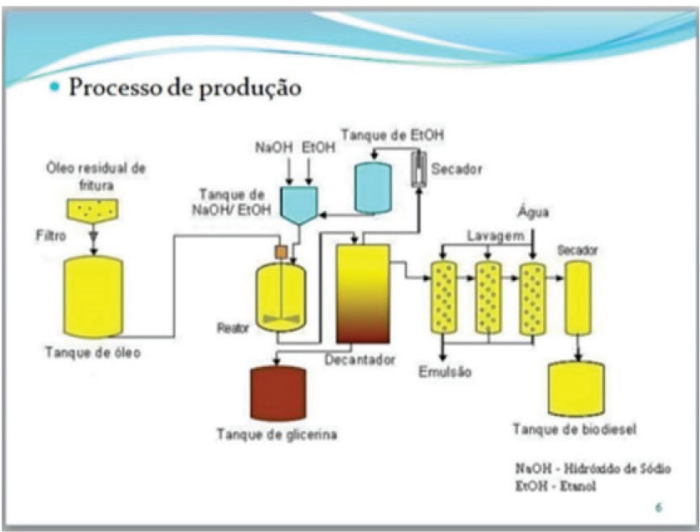

Slide 6

Figura 4. Slides 3, 5, 6 e 10 da apresentação do grupo G2

para a leitura mais ativa, visto que há a explicação de um trecho do AOP2, após a sua retomada. Identificamos esse aspecto no trecho da transcrição do slide 16:

[REFORMULAÇÃO] [RETOMADA] Essa remoção de ácidos graxos é coerente com aquele aumento de $\mathrm{pH}$ que eu falei no início, porque... É ... mostra efetivamente que houve remoção dos ácidos e o aumento de $\mathrm{pH}$ também comprova que houve remoção de ácidos.

O mesmo comportamento pode ser observado ainda para a complementação de ideias, que surge após alguma conclusão realizada pelo aluno expositor após a leitura do AOP2, de forma a complementar o seu sentido para os espectadores:

[RETOMADA] Então se nós deixássemos decantar esses coágulos iriam descer pro fundo e na alíquota teria menor quantidade de matéria orgânica. Quanto aos aspectos de matéria orgânica [COMPLEMENTAÇÃO] esse efluente poderia também ser reutilizado no processo.

No que se refere à retomada acoplada à inserção de exemplos, esta confirma a leitura crítica e de cunho reflexivo por parte do aluno expositor, visto que essa característica demonstra a integração às ideias dispostas no texto base. ${ }^{21}$ Verificamos tal ocorrência no slide 10, que tem um trecho de sua transcrição ilustrado a seguir:

[RETOMADA] A eletrofloculação é um processo no qual é gerada uma corrente elétrica no efluente... e ela gera um agente coagulante... O que que acontece? No ânodo a oxida-

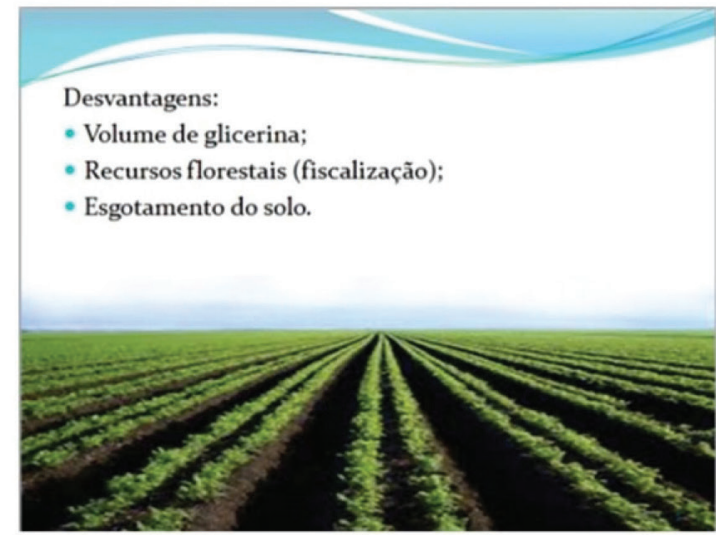

Slide 5

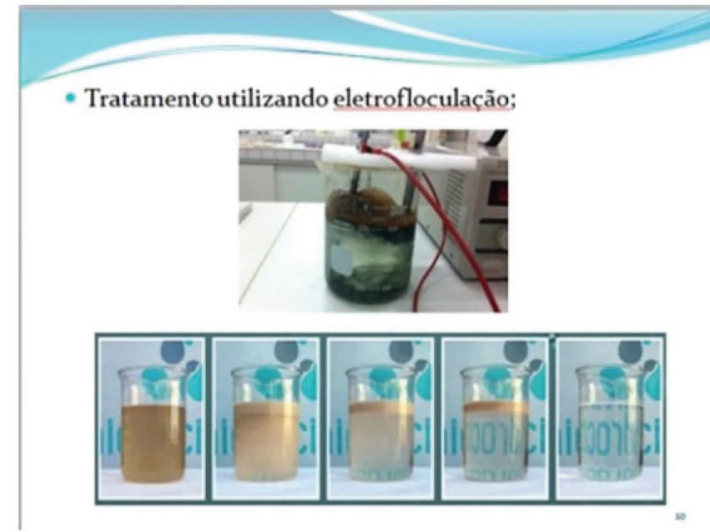

Slide 10

ção com metal de sacrifício... [INSERÇÃO DE EXEMPLO] geralmente alumínio ou ferro por serem baratos e, altamente... É, são altamente encontrados no mercado e são muito baratos para a indústria.

A construção de opinião própria pode ter sido acoplada às ideias do AOP2 ou elaboradas por temas a partir dele. ${ }^{21}$ Assim, a retomada antecedida pela construção de opinião própria, evidenciada no slide 8, no qual o aluno expositor demonstra a concordância com a efetividade do processo proposto pelos autores do AOP2. O trecho da transcrição referente a tal característica é apresentado a seguir:

[CONSTRUÇÃO DE OPINIÃO PRÓPRIA] Além disso, se nós conseguíssemos a reutilização dessa água no processo... É, manteríamos a efetividade do processo de lavagem porque esse processo de lavagem com água especificamente é extremamente efetivo na remoção dos resíduos e porque eu falei disso, de manter a efetividade do processo de lavagem com água, porque [RETOMADA] há outros estudos de tratamentos alternativos e os que mais se destacam utilizam adsorventes.

A reordenação tópica acoplada à retomada revela a organização das ideias a serem expostas e o julgamento do aluno expositor no que se refere à hierarquização dessas ideias, de modo que os tópicos foram reordenados a partir do AOP2, conferindo maior coerência em sua EO. No slide 14 podemos observar a ocorrência dessa característica, sendo que não há prejuízos ao sentido do AOP2 a 


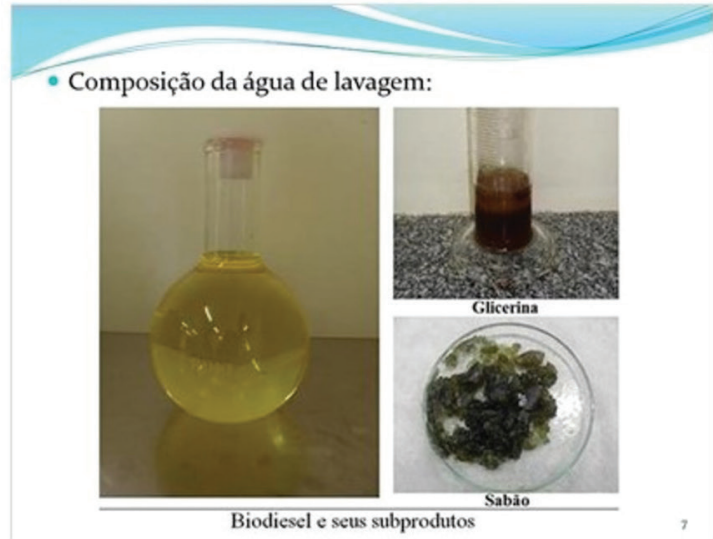

Slide 7

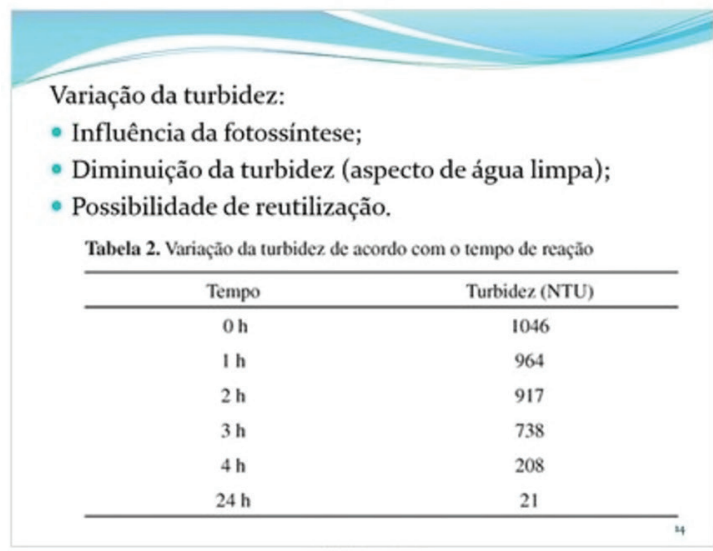

Slide 14

Figura 5. Slides 7, 8, 14 e 16 da apresentação do grupo G2

partir da reordenação tópica. O trecho referente a essa situação é apresentado a seguir:

[REORDENAÇÃO TÓPICA] [RETOMADA] A turbidez é essencial. Ela é uma análise essencial porque o efluente não pode ser descartado se estiver muito túrbido porque ele impede que a radiação solar passe pela água e impede o processo de fotossíntese. Ou seja, altera a atividade natural aquática.

Apresentamos, assim, uma breve discussão acerca da caracterização do desenvolvimento das EO e suas propriedades linguísticas, associadas à retomada, que foi a mais recorrente durante a EO do grupo G2. O aluno expositor, nesse contexto, demonstrou o domínio parcial da elaboração do gênero em questão e a leitura crítica e reflexiva acerca do texto base, uma vez que nas ocasiões julgadas oportunas por ele, foram tecidas complementações, acréscimo de informações, inserção de exemplos e reformulações.

Em linhas gerais, consideramos que os grupos G1 e G3, assim como G2, também realizaram modificações no texto base para potencializar o entendimento dos espectadores. Estas ocorreram de formas distintas e emergiram de acordo com o entendimento de cada um sobre o AOP estudado. Para citar alguns exemplos, o aluno expositor de G1 adicionou subtítulos ao texto original e elaborou um gráfico a partir de informações contidas no AOP. Já o aluno expositor de G3 se ateve no uso de somente imagens e gráficos presentes no texto, porém, os explicou de maneira que os colegas pudessem compreender o conteúdo estudado.

\section{Recapitulação e sintese}

Para Dolz et al. ${ }^{9}$ esta é uma etapa importante para retomar os

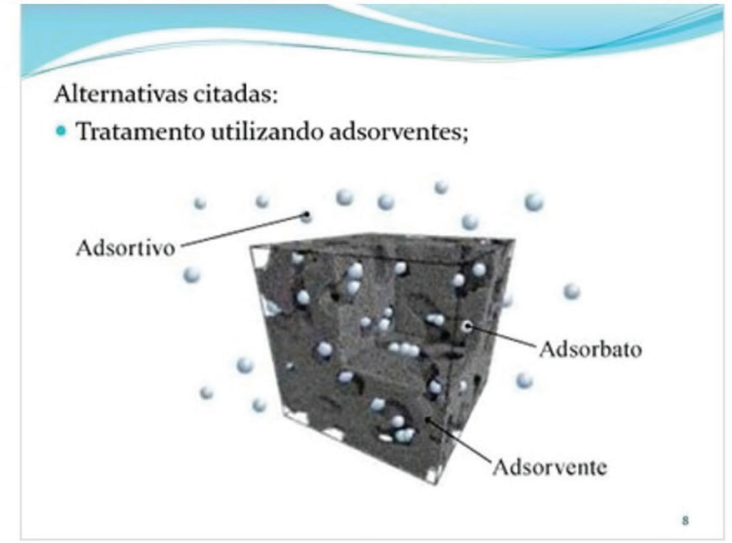

Slide 8

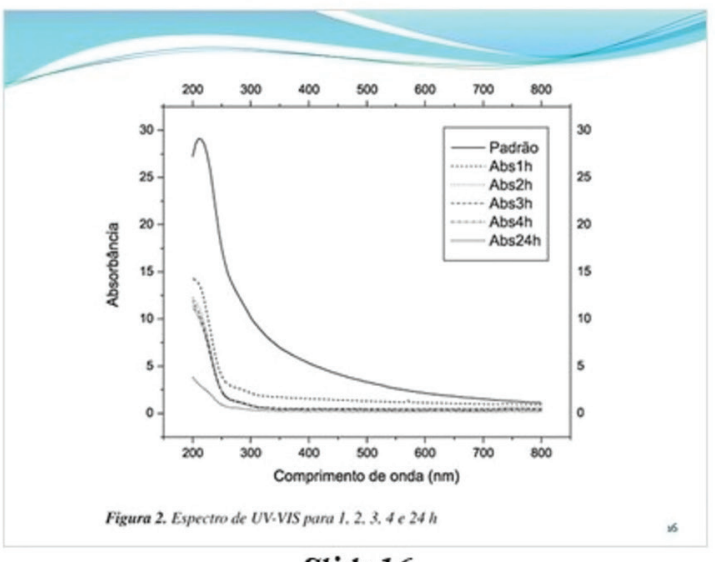

Slide 16

principais pontos da $\mathrm{EO}$ e por se caracterizar como uma fase de passagem entre a EO e suas duas etapas de conclusão, que serão apresentadas na sequência. Destacamos que o aluno expositor de G2 não contemplou tal etapa, de modo que esta desfalca a estrutura do gênero elaborado e demonstra a sua falta de domínio acerca da produção. Dessa forma, o aluno passa diretamente do slide 19, que é o último da etapa de desenvolvimento, e trata das discussões acerca dos resultados obtidos pelos autores do AOP2 para o slide 20, denominado conclusões gerais. Verificamos o mesmo comportamento para os grupos G1 e G3.

\section{Conclusão e encerramento}

A etapa da conclusão trata da comunicação da mensagem final sobre o texto base e também pode apresentar aos espectadores a existência de um problema novo, a partir do que foi dito na exposição, o que requer novos estudos e também o início de um debate, dentre outros aspectos. ${ }^{9}$ Já a etapa de encerramento deve ser simétrica à abertura, visto que comporta os agradecimentos aos espectadores. Assim como a abertura, é uma etapa bastante "ritualizada" e apresenta ainda uma característica de interação, distinta da ocorrida ao longo da exposição, por incluir, muitas vezes, o mediador, os espectadores etc. ${ }^{9}$ O slide 20 , que tratou da etapa de conclusão da EO está ilustrado na Figura 6.

O trecho da transcrição da fala do aluno expositor delimita a conclusão e o encerramento:

Bom, no geral, então, com esse processo nós podemos obter novecentos e cinquenta e cinco $\mathrm{ml}$ em um litro de líquido transparente de todos aqueles aspectos que eu falei, de $\mathrm{pH}$, de matéria orgânica e quarenta e cinco $\mathrm{ml}$ desse lodo 


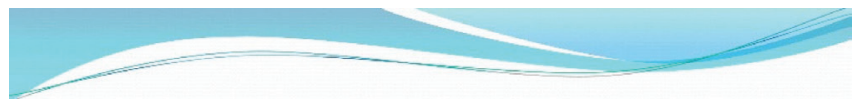

\section{Conclusões gerais}

\section{- $955 \mathrm{ml}$ de um líquido transparente e praticamente sem odor ( 24 horas de tratamento), $45 \mathrm{ml}$ de lodo;}

- Aperfeiçoamento: ganhos ambientais;

- Perfeitamente aplicável (comparação).

Figura 6. Slide 20 da apresentação do grupo G2

residual. $\mathrm{O}$ aperfeiçoamento dessa técnica geraria grandes ganhos ambientais inimagináveis porque geraria a economia de um grande volume de água. E ele é perfeitamente aplicável em comparação à eletrofloculação, é perfeitamente aplicável em escala industrial, em comparação com o uso de adsorventes. Porque, pensem vocês que o uso de adsorventes geraria maiores danos ao meio ambiente. Por quê? Porque o uso de adsorventes requer tratamento químico depois de sua utilização para que eles sejam reativados e isso gera novos resíduos químicos que também deveriam, vão ser tratados. Então, em comparação com a eletrofloculação ,,, A eletrofloculação é perfeitamente aplicável em comparação com os outros tratamentos. E é isso

Observamos que o aluno expositor retoma as ideias dispostas na conclusão do $\mathrm{AOP} 2$, de modo que há a retomada das ideias principais. Conforme indicado por Dolz et al. ${ }^{9}$ há a presença de uma mensagem final, que nesse caso, reafirma as potencialidades do tratamento aplicado pelos autores do AOP2, em comparação a outros tratamentos citados durante a EO. Por outro lado, o aluno expositor não se refere a novos problemas, necessidades de estudos posteriores e nem indica o início de um debate (que não ocorreu, segundo a proposta aplicada) ou o início das perguntas que poderiam ser realizadas pelos colegas. Dessa forma, o domínio do gênero elaborado se mostra parcial para a etapa de conclusão.

Em relação aos demais grupos, ambos retomaram as conclusões apresentadas nos AOP, assim como G2, de forma parcial. O aluno expositor de G1 apresentou, além das conclusões em tópicos, uma imagem do AOP, que fazia parte da seção Resultados e Discussão, para ilustrar o sucesso da técnica empregada. Já o aluno expositor de G3 destacou os bons resultados obtidos pelos autores e os pontos positivos da técnica por eles utilizada. Ambos não comentaram, assim como G2, os tópicos descritos, como a realização de estudos posteriores e não indicaram o início da etapa de perguntas pelos colegas.

No que se refere à etapa de encerramento, essa não foi evidenciada da maneira disposta por Dolz et al., ${ }^{9}$ de modo que não houve o ritual de agradecimento aos espectadores e ao professor. O encerramento por parte do aluno expositor de G2 se resumiu à fala "e é isso". Desse modo, inferimos que o encerramento não foi compreendido pelo aluno expositor, o que torna o domínio do gênero elaborado parcial. O uso da expressão para encerrar a apresentação pode ser tido como informal, o que implica na utilização adequada ao gênero produzido, e deixa evidente as falhas na apropriação dos padrões para a elaboração da EO. Por outro lado, os grupos G1 e G3 realizaram esta etapa de forma adequada, agradecendo os espectadores pela atenção após o término das apresentações.

Para Silva ${ }^{21}$ as ações envolvidas durante a EO dependem de fatores, além daqueles explicitados neste trabalho. Sendo assim, é importante destacar que é esperado que o aluno expositor também tenha conhecimento sobre o gênero que será produzido a fim de direcionar a sua apresentação; produza o gênero de modo claro, considerando os espectadores; seja capaz de produzir o gênero a partir do texto base, que envolve a utilização correta das características cognitivas e linguístico-discursivas envolvidas, dentre outros aspectos.

Assim, inferimos que os alunos expositores dos grupos G1, G2 e G3 foram capazes de produzir o gênero em questão, ainda que não tenham se apropriado de sua elaboração em todos os momentos. Diante da proposta realizada, tal elaboração do gênero se mostra como importante para cumprir os aspectos citados por Silva ${ }^{21}$ e tomar conhecimento de como se dá uma EO em âmbito acadêmico.

\section{CONSIDERAÇÕES FINAIS}

Os resultados apresentados indicam o domínio parcial do gênero EO pelos alunos expositores dos grupos analisados, com fragilidades concentradas principalmente nas subpartes denominadas na Tabela 4 de: introdução ao tema; recapitulação e síntese; encerramento. Tal constatação não desabona a qualidade das referidas EO, pois a maioria das subpartes foi satisfatoriamente contemplada, com destaque para aquela de complexidade elevada, que abarca o desenvolvimento e encadeamento dos diferentes temas. A associação dessas duas afirmativas permite a tessitura das seguintes considerações:

- Uma vez que a produção de todas as EO propiciou o desenvolvimento e encadeamento dos diferentes temas a contento, é possível afirmar que, para tanto, os alunos lograram sucesso na seleção das ideias principais dos autores dos AOP, na elaboração de slides a partir da progressão lógica de conteúdos e na utilização destes como material de apoio de forma coerente durante a exposição. Esse exercício não é trivial, especialmente para graduandos matriculados no segundo semestre, a quem poucas oportunidades de contato com os gêneros EO e AOP costumam ser oferecidas. Parte da capacidade exibida para levar tal exercício a cabo pode ser creditada ao cumprimento de todas as etapas cuidadosamente planejadas da atividade didática em si, que envolveu, além da leitura guiada dos AOP, a produção de textos argumentativos e a participação no PPR. Dessa maneira, o presente artigo, ao caracterizá-la de forma detalhada, possibilitando ao leitor inclusive o acesso a recurso instrucional empregado no formato de rubrica (Quadro 1S, material suplementar), tem caráter inédito na literatura nacional voltada ao ensino de química, com potencial para subsidiar professores interessados na condução de ações vinculada à elaboração dos gêneros EO e AOP na universidade.

- As fragilidades observadas nas EO, concentradas nas etapas iniciais e finais, sugerem que, da mesma forma como são concedidos espaços em disciplina da graduação para o ensino e aprendizagem da produção de textos que circulam na academia, como resumos, pôster, também deve existir lugar para a produção de EO. A forte tradição de valorização da escrita nas disciplinas, em detrimento do oral, precisa ser superada a partir do oferecimento de orientações para a produção do gênero em questão, o que pode acentuar a performance dos alunos na esfera acadêmica. Nessa perspectiva, providenciar recomendações que venham a fortalecer o entendimento dos expositores sobre a relevância das etapas mencionadas é uma necessidade que emerge da análise dos dados. Ou seja, a partir da organização interna da EO, explicitar as partes que a compõem, com ênfase naquelas que são ritualizadas em âmbito acadêmico é relevante. 
Muitas vezes os alunos não têm a chance de aprender a produção do gênero antes da apresentação em eventos científicos, em disciplinas (como critério de avaliação), e em tantas outras situações nas quais são solicitados a elaborar EO. Desse modo, este trabalho tem o propósito de fomentar discussões acerca desse gênero na esfera acadêmica e de quais processos possibilitam ou dificultam a sua produção, para que ele venha a atender aos seus objetivos e às suas funções comunicativas e não seja efetivado apenas como uma atividade avaliativa.

Por fim, entendemos que atividades que envolvam a leitura, compreensão e produção textual no âmbito do ensino superior devem ser encorajadas, por serem intrínsecas à academia e à formação profissional dos estudantes.

\section{AGRADECIMENTOS}

O presente trabalho foi realizado com apoio da Coordenação de Aperfeiçoamento de Pessoal de Nível Superior - Brasil (CAPES) Código de Financiamento 001, e da Fundação de Amparo à Pesquisa do Estado de São Paulo (FAPESP) - Processo: 2016/20073-0.

\section{MATERIAL SUPLEMENTAR}

A rubrica para dar embasamento à elaboração e análise dos textos produzidos pelos estudantes pode ser encontrada em http://quimicanova.sbq.org.br, em formato PDF, com acesso livre.

\section{REFERÊNCIAS}

1. Brasil. Conselho Nacional de Educação. Parecer CNE/CES 1.303/2001, de 6 de novembro de 2001. Diretrizes Curriculares Nacionais para os Cursos de Química. Diário Oficial da União, Brasília, 7/10/2001. Seção 1, p. 25.

2. Oliveira, J. R. S.; Queiroz, S. L.; Quim. Nova, 2012, 35, 851.

3. Oliveira, J. R. S.; Queiroz, S. L.; Quim. Nova, 2014, 37, 1559.

4. Oliveira, J. R. S.; Queiroz, S. L.; Quim. Nova, 2015, 38, 553.
5. Barros, A. A. D.; Garcia, V. M.; Yamashita, M.; Francisco Júnior, W. E.; Revista Amazônica de Ensino de Ciências 2012, 5, 83; Francisco Júnior, W. E.; Investigações em Ensino de Ciências 2011, 16, 161; Oliveira, J. R. S.; Queiroz, S. L.; Alexandria 2011, 4, 89; Wenzel, J. S.; Maldaner, O. A.; Quim. Nova Esc. 2014, 36, 314.

6. Francisco Júnior, W. E.; Quim. Nova Esc. 2010, 32, 220.

7. Silva, A. V. L.; Revista Virtual de Letras 2016, 8, 43.

8. Freitas, P. R.; Dissertação de Mestrado, Universidade Estadual de Campinas, Brasil, 2016.

9. Dolz, J.; Schneuwly, B.; Pietro, J-F.; Zahnd, G. Em Gêneros orais e escritos na escola; Schneuwly, B., Dolz, J., eds.; Mercado de Letras: Campinas, 2004, cap. 9.

10. Bakhtin, M. Em Estética da criação verbal; Bakhtin, M., ed.; Martins Fontes: São Paulo, 1979, cap. 3.

11. Almeida, R. L. L.; Mesquita, E. M. C.; Alves, M. M.; Interfaces da Educação 2018, 9, 43.

12. Goffman, E.; Façons de parler, Éd. De Minuit: Paris, 1987.

13. Marcuschi, L. A.; Produção textual, análise de gêneros e compreensão, Parábola Editorial: São Paulo, 2008.

14. Oliveira, J. R. S.; Porto, A. L. M.; Queiroz, S. L.; Revista Educación Química em Línea 2014, 25, 35.

15. Santos, G. R.; Queiroz, S. L.; Ciência \& Educação 2007, 13, 193.

16. Sá, L. P.; Kasseboehmer, A. C.; Queiroz, S. L.; Ensaio 2014, 16, 147.

17. Toulmin, S. E.; Os usos do argumento, Martins Fontes: São Paulo, 2001.

18. Brito, J. F.; Ferreira, L. O.; Silva, J. P; Ramalho, T. C.; Quim. Nova 2012, 35, 728 .

19. Meneses, J. M.; Vasconcelos, R. F.; Fernandes, T. F.; Araújo, G. T.; Quim. Nova 2012, 35, 235.

20. Paula, A. J. A.; Krügel, M.; Miranda, J. P.; Rossi, L. F. S.; Costa Neto, P. R.; Quim. Nova 2011, 34, 91.

21. Silva, A. V. L.; Tese de Doutorado, Universidade Federal de Minas Gerais, Brasil, 2013.

22. Oliveira, J. R. S.; Queiroz, S. L.; Comunicação e linguagem científica: guia para estudantes de química, Editora Átomo: Campinas, 2007.

23. Silva, A. V. L.; Revista Memento 2011, 2, 70. 